\title{
Preface \\ Preface to the Supplement: Perinatal and Neonatal Health Interventions Research
}

Journal of Perinatology (2002) 22, S1 doi:10.1038/sj.jp.7210799

This supplement to the Journal of Perinatology details a meeting held in Kathmandu, Nepal in April/May of 2001. This workshop presented a global perspective to the state of newborn medicine and offered a forum to identify problems and to prioritize changes in care offered to mothers and their newborns. The goal was to implement survival interventions that would decrease perinatal and neonatal mortality and morbidity.

Regional issues in Asia, Africa, and Latin America are discussed freely. Research plans are detailed and the results from recent research are presented, with a global review of these interventions. The organizers of this meeting have emphasized the importance of understanding the local beliefs and practices that can directly and indirectly affect provision of maternal and neonatal care.

Perinatologists and neonatalogists in the United States have very little knowledge of the state of their specialties in other countries of the world. It would be a wonderful experience for many of us to visit other countries to broaden our perspectives and allow for a greater understanding of the state of perinatal and neonatal care in the world. A special thanks to Gary Darmstadt who assisted the editors in producing this supplement to the Journal of Perinatology.

Gilbert I. Martin, MD Editor, Emeritus 